\title{
Entrevista com a historiadora Adeline Rucquoi
}

\section{Susani Silveira Lemos FRANÇA*}

\section{Leandro Alves TEODORO**}

Para acompanhar o dossiê Escritos e Imagens do Mundo Luso-Brasileiro (séculos XIIIXVIII), dedicado a refletir sobre como duas sociedades, a portuguesa e a brasileira, se articularam ao longo de séculos, este número da revista traz uma entrevista com uma das mais importantes especialistas francesas em estudos sobre a Península Ibérica Medieval. Da história urbana castelhana aos estudos sobre formas de devoção medieval, passando pela gênese do Estado Moderno e vários outros temas de história social, Rucquoi legou-nos uma obra não apenas vasta, mas sobretudo recheada de questionamentos que inspiraram estudos posteriores.

Além do clássico traduzido para o português, História Medieval da Península Ibérica (Estampa,1995), e outros estudos de síntese, como L'Espagne médiévale (Les Belles Lettres, 2002), merecem destaque: Valladolid au Moyen Âge (1080-1480) (Publisud, 1993), Aimer dans l'Espagne médiévale: Plaisirs licites et illicites (Les Belles Lettres, 2008) e Mille fois à Compostelle: Pèlerins du Moyen Âge (Les Belles Lettres, 2014).

Susani S. L. França e Leandro Alves Teodoro - Na sua trajetória intelectual, quando transita entre reflexões sobre o poder e aquelas sobre peregrinos, mulheres, relações afetivas, etc., sua interrogação é conduzida por uma mesma pergunta de fundo, algo que uniria esses aspectos? Ou concebe cada aspecto sem propriamente pensar em unidades?

Adeline Rucquoi - Minha "trajetória intelectual", minhas reflexões sobre a história e minha maneira de abordar temas que podem parecer, à primeira vista, um pouco "desconexos" - as cidades, o poder, o amor, os peregrinos, a identidade, as mulheres, a nobreza - devem muito aos

Entrevista concedida em francês e traduzida por Leandro Alves Teodoro.

* Susani Silveira Lemos França é professora Livre-Docente em História Medieval do Departamento de História e do Programa de Pós-graduação em História da Universidade Estadual Paulista - UNESP/Franca.

** Leandro Alves Teodoro é pós-doutorando em história pela UNESP/Franca sob a supervisão da Profa. Dra. Susani Silveira Lemos França e com bolsa FAPESP/CAPES (Processo no 2014/13125-9). 
mestres que eu tive não só durante meus estudos, mas ao longo de toda minha carreira. Jean Gautier-Dalché (1913-2010) foi quem me iniciou na Espanha medieval e quem me transmitiu seu amor por essa Península. Michel Mollat du Jourdain (1911-1996), que foi meu orientador na tese, atraiu minha atenção para os pobres e para o papel destes no seio da sociedade medieval. Com Jacques Le Goff (1924-2014) e Jean Delumeau (1923- ), descobri a antropologia histórica e a necessidade de o historiador recorrer a domínios pouco explorados até então, como a literatura, a arte, a teologia, o direito, a hagiografia, a arqueologia, a filosofia, a liturgia e muitos outros, a fim de interrogar as fontes contextualizando-as. Os cursos de Michel Foucault (1926-1884) permitiramme entender certos temas com outra perspectiva e trouxeram-me um interesse especial às "palavras por dizer" (mots pour le dire), à "arqueologia do saber" "Archéologie du savoir". Enfim, Yan Thomas (1943-2008), cujo seminário de direito romano segui durante anos, mostrou-me a importância das bases legislativas da sociedade medieval hispânica e a precisão do vocabulário jurídico.

A "questão de fundo" de que falam é para o historiador, mas também para o filósofo e todo especialista em ciências humana, a do homem. Compreender o homem, compreender a sociedade e tentar responder às questões ontológicas: Quem somos nós? De onde viemos? Onde estamos? Homo sum, humani nihil a me alienum puto, dizia Térence (190-159). "A história total” foi uma das ambições de Marc Bloch (1886-1944) e de Lucien Fèvre (1878-1956), colocada em prática na revista dos Annales durante numerosos anos. Não é, portanto, tão difícil de abordar temas "humanos" diversos para tentar responder a esta única questão de fundo.

No caso de meus estudos que são centrados na Península Ibérica da Idade Média, o primeiro problema que se colocava era alcançar o conhecimento do ambiente social, bem como do mental em que evoluíram, entre os séculos $\mathrm{V}$ e XV, os habitantes de diversos reinos peninsulares. Eu tinha aplicado, portanto, os métodos da antropologia histórica: como viviam eles? O que comiam? Como trabalhavam e quais eram suas ferramentas? O que liam e o que escreviam? Quais eram suas referências históricas, literárias, artísticas? Em que acreditavam? Que palavras utilizavam para nomear as coisas? Quem e como amavam? Quais eram os papéis masculino e feminino? Como se comportavam em torno de seus semelhantes? O que temiam e o que esperavam?

Foi certamente necessário que eu fizesse abstração de tudo o que eu havia aprendido sobre a França medieval durante meus estudos, a fim de não "transpor" uma grade de leitura preestabelecida sobre os textos que eu lia. Qualquer pessoa que passa um tempo num país estrangeiro sabe: temos de reaprender desde as coisas mais triviais até os "falsos cognatos", sob a pena de jamais compreendermos inteiramente o país que nos acolhe. Através do estudo de uma cidade, Valladolid, e posteriormente da "gênese do Estado Moderno" e, enfim, do poder e de seus fundamentos ideológicos e históricos, tentei compreender, "do interior", o mundo hispânico 
medieval, suas especificidades e o que o distinguia e o que partilhava com o resto do Ocidente cristão da época. No seio dessa visão global - na medida do possível, dado que sujeita às fontes que sobreviveram -, analisar de mais perto este ou aquele tema, à mercê de um convite, de um colóquio, de uma interrogação nascida de outra pesquisa, de uma proposição de publicação - é apenas o desdobramento de uma parte do todo. Quem contribui, por sua vez, para melhor definir e melhor compreender o todo? Afinal, quem pode se gabar de "tudo" conhecer?

Susani S. L. França e Leandro Alves Teodoro - Em termos de procedimentos de pesquisa, quais costumam ser seus pontos de partida: aquilo que veio a se tornar fundamental para nós ou o que era possível dentro do universo medieval? Em outras palavras, seu olhar é do presente para o passado ou seu ponto de partida são as formulações dos próprios medievais?

Adeline Rucquoi - Um colega dos Estados Unidos me disse um dia que a história era como uma criança bem educada: ela responde somente se nós lhe falamos e ela só responde à questão que lhe é colocada. Ora, o historiador, como filho de seu tempo, coloca questões para a história sempre ligadas ao momento em que vive, sejam temas sociais - o feminismo, o lugar das religiões, a violência, a identidade - ou temas que lhe são mais pessoais -, a história dos judeus quando se é judeu, das mulheres quando se é mulher, das guerras recentes em função de uma história familiar, ou uma história da identidade quando se pertence a várias culturas. O historiador procura com frequência responder a problemas atuais buscando soluções dadas no passado. Nesse sentido, uma obra como a de Norman Frank Cantor (1929-2004), Inventing the Middle Ages (New York, 1991) é tão esclarecedora quanto o estudo da historiografia contemporânea sobre os temas estudados. Como não relacionar, desde 1830, a conquista da Argélia pelos franceses com a exaltação feita pelos historiadores de um papel "civilizador" de Cluny na Espanha do século XI invadida pelos mulçumanos?

Uma vez escolhido o tema, um conhecimento aprofundado da historiografia permite frequentemente "desconstruir" os postulados colocados como verdades universais. É por isso, pois, que o historiador deve ler as fontes e dar voz - escrita, pintada, esculpida - àqueles que ele quer conhecer, ou seja, aos homens da Idade Média. Ele deve ler, “escutar”, diria eu, seus testemunhos e tomá-los pelo que são: testemunhos subjetivos, criados num contexto específico, respondendo às necessidades e aos objetivos que devem ser conhecidos, que se sobrepõem ou se contradizem, que empregam um vocabulário que não é o nosso e envolvem referências que, às vezes, nos escapam. $\mathrm{O}$ inquérito, pois trata-se de um verdadeiro inquérito, deve partir desses testemunhos e analisá-los à luz de seu contexto. 
Observemos um exemplo: duas palavras aparecem repetidas com certa frequência nos textos da Espanha Medieval: tierra e natural. Tierra é utilizada para designar o reino ou a Península e natural, o laço que une os habitantes a essa tierra. Na França, os habitantes são os "súditos" do rei. Na Espanha, eles são os naturales de la tierra; quanto ao rei, se levarmos em consideração a formulação da $I^{a}$ Partida, ele é señor da mesma tierra. Esses termos são compreendidos somente na perspectiva da filosofia e do direito elaborados no século XII. Natura, ide st Deus, escrevem os filósofos da escola de Chartres que identificam, assim, a Criação ao Criador, enquanto os juristas de Bolonha dividem os direitos em três "níveis": ius civilis ou direito positivo, ius gentium ou direitos do homem e ius naturalis ou direito divino. A Espanha é, dessa forma, a beata Hispania que proclama Vincent d'Espagne em torno de 1215-1220 e, no plano divino, nenhuma "sacralização" do poder é necessária ou concebível, e menos ainda uma "legitimação".

Se, portanto, o ponto de partida da investigação é muitas vezes devido a razões pessoais ou de atualidade, sua realização só pode se efetuar a partir das evidências fornecidas por aqueles que se quer estudar e que se deve sistematicamente contextualizar; por isso, a análise do poder - como aquela das mulheres ou do culto dos santos - não será a mesma no século VII e no XI ou no XV, em razão do contexto no qual ela se inscreve. O historiador é semelhante ao herói do romance de Isaac Asimov (1920-1992), The End of Eternity (1955), que viaja por tempos e séculos diferentes a partir de um ponto fixo, o seu próprio tempo.

Susani S. L. França e Leandro Alves Teodoro - Depois de anos como diretora de pesquisa do Centre de Recherches Historiques de L'École des Hautes Études en Sciences Sociales, qual sua análise sobre o interesse pela história medieval da Península Ibérica na França? Vêm surgindo novos centros de pesquisa? Há jovens pesquisadores que têm se destacado por uma abordagem diferenciada? Com a especialização precoce e uma certa tecnicidade na produção do conhecimento, podemos ainda esperar por grandes historiadores ou sínteses renovadoras?

Adeline Rucquoi - Durante a última década, o interesse pela história medieval da Península Ibérica - com exceção da Espanha muçulmana, que fascina os ocidentais do século XXI, fascínio esse que vem desde o século XIX - conheceu, na França, certo declínio. Isto é devido a uma série de causas que inclui notadamente a aposentadoria, por idade, de especialistas da área, autores de teses e de trabalhos importantes, sem que uma nova geração esteja pronta para cumprir o mesmo papel.

A ausência frequente de jovens pesquisadores é devida ao sistema de concursos nacionais na França. A agregação de história, que se prepara nas universidades ou nas grandes escolas especializadas, como l'École Normale Supérieure, e que abre as portas para os cargos acadêmicos, 
obriga os candidatos a estudarem em profundidade uma questão para cada época histórica e duas outras em geografia. Essas diversas questões de agregação mudam a cada dois anos. A escolha dos temas, escolha temática, cronológica e geográfica - a questão de agregação em 2015-2016 em história medieval é: "Governar no Islã entre o século X e o século XV (Iraque até 1258, a Síria, Hijaz, Iêmen, Egito, Magrebe e Al-Andalus)"; em 2013-2014, a questão era: "Guerra e sociedade de 1270 a 1480" (Reino da Escócia, reino da Inglaterra, reino da Irlanda, reino dos Países Baixos, reino da França e margens ocidentais do Império, espaço italiano excluído) - suscita vocação na hora de escolher um domínio de pesquisa sobre o qual se faz uma tese. Ora, a Espanha medieval desapareceu dos programas da agregação há quinze anos (a escolha do programa é feita por membros do júri, que optam geralmente pela própria área de pesquisa). Alguns temas ainda atraem, portanto, os jovens pesquisadores franceses, como os Anglo-saxões, al-Andalus e a Espanha mulçumana.

Seria, no entanto, falso afirmar que não existem mais jovens pesquisadores interessados pela história dos reinos cristãos da Península. Mas as novas exigências do ciclo universitário, que impõem que uma tese de doutorado seja acabada em três anos, quatro no máximo, não permitem evidentemente um conhecimento suficiente não só do tema escolhido, mas também de seu contexto; a fortiori se trata de um país estrangeiro do qual temos, em relação aos estudos franceses, vagas noções. A tentação é, portanto, forte para escolher um tema de pesquisa próprio da historiografia francesa - tais como "sacralização", legitimação -, de analisar com "ferramentas" elaboradas pela França e procurar resultados parecidos com aqueles que são conhecidos na França. É impossível, em um curto espaço de tempo, "impregnar-se" do país e de sua história, encontrar referências próprias do lugar e da época, compreender o vocabulário utilizado e situar o tema num vasto contexto sociocultural. A entrada na vida profissional, que segue à defesa da tese, não favorece um verdadeiro aprofundamento de conhecimento: é necessário publicar muito e rápido, participar de projetos (escolhidos por outros), ou dirigi-los, e de colóquios (com temas variados), ensinar, orientar alunos, aceitar tarefas administrativas, preparar uma "habilitação para orientar pesquisas" ("habilitation à diriger des recherches")... Falta tempo, a reflexão que requer o ofício do historiador e, mais ainda, quando se trata de um domínio geográfico e mental diferente, torna-se muito difícil, de maneira que o conformismo está na moda e a aplicação pura e simples de métodos e de resultados próprios da historiografia francesa conforta os colegas em seus hábitos e suas certezas. É o que Marc Bloch chamava de "a rotina erudita" e "o empirismo disfarçado de senso comum". Também muitos investigadores estrangeiros, que não conhecem suficientemente os jogos franceses, se deixam influenciar por estes trabalhos, os quais são pálidas cópias de pesquisas realizadas na França. 
Eu estou, de fato, pessimista, a curto e médio prazo, quanto à capacidade da França de produzir, na área de história medieval da Península Ibérica, grandes sínteses ou linhas de pesquisa realmente inovadoras. A dimensão específica da história é o tempo e o tempo é negado aos historiadores, jovens ou nem tão jovens assim.

Susani S. L. França e Leandro Alves Teodoro - A sua trajetória notabiliza-se não apenas pelo número de obras publicadas, mas também por sua participação em importantes centros internacionais de pesquisa, como a Academia Mexicana de la Historia, a Academia Portuguesa da História, a Real Academia de la Historia de la España, a Société Nationale des Antiquaires de France, a Association for Spanish and Portuguese Historical Studies, entre outros. Qual seria o papel dessas instituições para o desenvolvimento de pesquisas no campo da história medieval?

Adeline Rucquoi - As academias têm muitas vezes uma má reputação, exceto para aqueles que aspiram a fazer parte delas. Elas são vistas como instituições enrijecidas, duras, vestígios do passado sem utilidade. Às vezes elas se opõem às associações que se agrupam por países ou sobre dado tema trabalhado por especialistas na matéria e que têm às vezes um papel ativo na defesa dos interesses das corporações. Porém uns e outros exercem papéis complementares, e eu tenho de saudar particularmente seus membros.

As associações, que existem desde inúmeras décadas, têm às vezes tendência, como na França, de se tornarem sindicatos cuja principal preocupação é "defender", de maneira corporativista, a profissão e seus privilégios. Como todo sindicato, a Société des Historiens Médiévistes de l'Enseignement Supérieur Public (SHMESP) prende-se "às aquisições" e recusa toda evolução e toda mudança. Este não é, naturalmente, o caso para todas as associações nacionais, mas a defesa da própria disciplina e a reflexão sobre a pesquisa, seus campos, a metodologia, bem como sobre seus instrumentos cedem lugar para as preocupações administrativas, para a "cozinha" universitária. Há que se ver somente o pouco caso que se teve com as instituições de pesquisa, como o CNRS na França ou o CSIC na Espanha.

As academias permanecem lugares de erudição, onde as questões de cargos universitários, concursos, constituição de comissões ou de júris de teses têm pouco espaço. As sessões das academias são frequentemente ocasiões para escutar comunicações sobre descobertas recentes, e elas misturam historiadores de todas as épocas, tendo às vezes historiadores de arte, de literatura e arqueologia. Infelizmente, as academias difundem pouco os temas que são abordados ao longo de suas sessões, temas esses que não saem sempre dos muros da venerável instituição. É necessário, portanto, saudar iniciativas como as tomadas pela Real Academia de la História, na Espanha, que 
publica os trabalhos de seus membros e pela Académie et Institut de France, que envia pela internet a todos os que desejam uma carta semanal de informações. Esta academia também disponibiliza

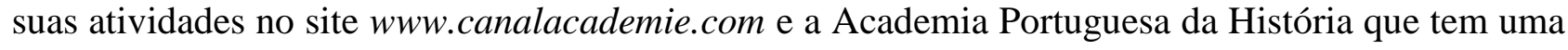
página no Facebook (para aqueles que têm inscrição na rede social).

Numa altura em que os governos ocidentais assumem uma política que tende a minimizar e, sem dúvida, a suprimir, com o tempo, a pesquisa em ciências humanas e sociais - a qual já foi o florão de centros como o CNRS, o CSIC ou o CNR italiano, a favor de um única pesquisa aplicada nas ciências ditas "exatas", de fato, ciências economicamente mais rentáveis num curto prazo - e numa altura também em que muitas associações se preocupam apenas com interesses corporativistas, se as academias forem capazes de se abrir e se adaptar ao mundo atual, estas poderão desempenhar um papel motor na pesquisa.

Susani S. L. França e Leandro Alves Teodoro - Em alguns momentos da sua trajetória, a senhora elaborou obras como L'Espagne médiévale, voltadas para um público não especializado. Qual o papel desse tipo de obra para a consolidação dos estudos medievais? Haveria ainda, na França, resistência por parte de alguns historiadores em aceitar o avanço da publicação de obras para grandes públicos?

Adeline Rucquoi - É certo que uma tradição anglo-saxônica tende a reservar obras científicas somente aos olhos de seus colegas, tanto porque eles são considerados capazes de julgar o valor desses escritos, quanto porque eles são muitas vezes vistos como instrumentos a serviço de uma carreira acadêmica. A imposição desses modelos é forte e ninguém se sente na obrigação de sacrificá-los.

Ora, a tradição francesa espera que os historiadores escrevam também obras de divulgação para um público cultivado e interessado. Marc Bloch, na obra Apologia da história ou o Ofício do historiador (redigida em 1941 e publicada em 1949), considera que o historiador tem um dever para com seus contemporâneos: "Tendo os homens como seu objeto de estudo, os quais nos escapam à compreensão, não teríamos apenas o sentimento de realizar parte de nossa missão?” E ele acrescenta que a recusa à vulgarização contribui para "entregar, sem defesa, a massa de leitores aos falsos brilhantes de uma pretensa história, da qual a ausência de seriedade, o pitoresco de fancaria, os partis pris políticos pensam ser resgatados por uma imodesta certeza" (Apologia da História. Ou o Ofício do historiador. RJ: Jorge Zahar, p. 95).

Se a história é, como dizia Cícero (c. 106 a. C.-43 a. C), magistra vitae, ela deve ser difundida. Essa disponibilização para o grande público de pesquisas científicas sobre a Idade Média 
foi destacada na França, notadamente por Georges Duby (1919-1996) num programa de televisão; por Jacques Le Goff (1924-2014) na rádio; por Jean Favier (1932-2014) em várias obras; por numerosos historiadores em revistas de boa vulgarização. Visto que uma obra pode ser ao mesmo tempo séria e muito acessível. Esse é o lugar onde a história se une à literatura. A História, para Isidoro de Sevilha, era a narratio rei gestae e ele especificava que situava essa disciplina no capítulo da gramática, pois “o que é digno de memória é confiado às letras”; um glossário espanhol do século X, compilado por San Millán de la Cogolla, define a história como rei preterite ratio, fazendo assim passar da gramática para a dialética. Em todos os casos, a história é uma narrativa, e a seriedade da pesquisa não ganha quando transmitida por uma língua abstrusa e reservada aos iniciados. Parece-me que a clareza de estilo é um sinal de respeito ao leitor, seja este quem for.

Mas para responder inteiramente à questão que me foi colocada, eu acrescentaria que os romances e os filmes históricos têm certamente feito muito para suscitar nos jovens leitores e espectadores um interesse pela história. Na França, de Victor Hugo (1802-1885) e Alexandre Dumas (1802-1870) à Maurice Druon (1918-2009), no mundo dos múltiplos Ivanhoé, Robin Hood aos atuais "Moi Claude, empereur" ou "Les Tudors", as obras desempenham um papel fundamental em uma vocação, mesmo que esse papel não seja sempre consciente ou confesso. Cabe talvez aos historiadores o papel de encontrar, sob uma forma legível, a ligação entre a ficção romanesca e uma perspectiva histórica séria.

Susani S. L. França e Leandro Alves Teodoro - O estudo da peregrinação é um dos focos de interesse das suas pesquisas. No que diz respeito às viagens para o oriente, essa prática religiosa de retorno a um lugar celebrado pela memória cristã leva também a contatos com o desconhecido ou o pouco conhecido. Na Península Ibérica, este aspecto das peregrinações seria também relevante ou outras peculiaridades se destacam?

Adeline Rucquoi - O estudo da peregrinação a Santiago de Compostela (e não a peregrinação em geral) se inscreve, para mim, no conjunto de minha pesquisa sobre a Península Ibérica medieval. Essa pesquisa inclui, evidentemente, o estudo da imagem que os "outros" fizeram da Espanha. Nessa perspectiva, a peregrinação, que drenou milhares de peregrinos de toda a Europa e do Oriente Médio para santuários da Galiza, pode permitir apreender uma das imagens veiculadas no mundo. A peregrinação é uma viagem e, como todo viajante, o peregrino, que deixa um testemunho escrito de seu itinerário e de suas impressões, traz elementos interessantes.

A peregrinação a Compostela oferece elementos que podem explicar seu sucesso. A peregrinação à Terra Santa é, contudo, mais longa. Esta leva o peregrino às origens de sua fé, para 
lugares bíblicos e evangélicos, ao berço do cristianismo. Mas trata-se de uma viagem dispendiosa é necessário pegar um barco que por vezes tem de esperar por semanas - e fortemente “emoldurada". Desde a retomada de Jerusalém pelos mulçumanos, é difícil circular, e a partir do século XIV, é necessário ser guiado pelos franciscanos, ser escoltado por eles, fazer, pois, uma visita acompanhada e retornar ao porto com a mesma escolta. Os perigos são inúmeros e, as extorsões, múltiplas. A peregrinação a Roma, que se desenvolve a partir do século XIII, é uma visita ao poder da Igreja, porque o Papa ali reside (geralmente) e os bispos regularmente ali se reúnem. Os peregrinos vão visitar as tumbas dos primeiros mártires, fundadores da Igreja, e também procuram ver de perto o Soberano Pontífice.

A peregrinação a Santiago de Compostela é a da esperança, dizem os autores do Codex Calixtinus no século XII, uma vez que conduz o peregrino ao oeste, no sentido da marcha do sol, isto é, de seu alvorecer ao seu entardecer. Este deslocamento é assim comparável à "peregrinação da vida humana", do nascimento à morte. É igualmente um centro da memória cristã, porque ali se venera um dos apóstolos mais próximos de Cristo, testemunho de sua transfiguração e primeiro apóstolo a ser mártir. Mas é, sobretudo, uma viagem que se efetua pelo mar ou pela terra e que permite a descoberta de regiões de difícil acesso, de santuários então em voga e de lendas apregoadas. No retorno, o peregrino torna-se um devoto de Santiago, por isso, a ele ergue altares e igrejas e, em sua honra, confrarias e hospitais. Desse modo, é mantida, por toda Europa, a presença do patrono da Espanha.

Susani S. L. França e Leandro Alves Teodoro - Um dos pontos salientes na sua obra é a convivência na Península Ibérica de judeus, árabes e cristãos, em especial no que diz respeito à prática da escrita. Por que, entretanto, Portugal e Espanha não tiveram o mesmo nível de desenvolvimento do saber escrito? Que especificidades de cada território a senhora considera decisivos na demarcação das duas experiências históricas?

Adeline Rucquoi - Como vocês sabem, para um medievalista, o período que ele estuda se estende, aproximadamente, entre os séculos V e VI e o XV, entre 500 e 1500. Portugal, como uma entidade separada do resto da Espanha, só aparece depois de meados do século XII, um pouco tardiamente, quando se constitui em reino. O seu tamanho é reduzido e, consequentemente, o número de seus scriptoria também. Uma Espanha que, aliás, não existe mais no século XII, porque está dividida no reino de Aragão, reino de Castela, reino de Granada, reino de Navarra e de Portugal. Este último também inicia uma verdadeira política de "separação" em relação ao resto da Península após a vitória de Aljubarrota sobre os castelhanos (1384) e após a necessidade de uma dinastia ilegítima, a 
de Avis, de assegurar seu poder, em particular pela escrita. As comparações entre esses diversos principados não podem ser feitas, a não ser quando úteis ou necessárias, e somente a propósito dos quatro últimos séculos da Idade Média.

A ausência ou a diminuição da presença da escrita na Península, enquanto é analisada, responde a inúmeras causas. A mais evidente e mais certa são as catástrofes naturais, inundações e incêndios sobretudo, as quais sabemos que foram várias. Outra causa é a guerra e suas destruições, a guerra contra os mulçumanos, contra os reinos vizinhos ou as guerras civis, estas tiveram como consequência a perda de muitos escritos, como se pode constatar após a pilhagem de Barcelona de 985. O uso precoce do papel como suporte da escrita, no século X em Al-Andalus e no XII nos reinos cristãos, pode ser apontado igualmente como causa, em razão da fragilidade deste material. Finalmente, existem duas outras possíveis causas, específicas para os países de direito escrito e, portanto, de longa tradição bíblica, onde boa parte da população aprendeu a ler e até escrever. A abundância de escritos podia tirar-lhes o caráter quase "sagrado" que esses tinham em regiões menos alfabetizadas, o que facilitava sua destruição quando não fossem mais considerados úteis. Como nos tempos atuais em que estamos destruindo a cada dia folhetos, jornais velhos, notas manuscritas obsoletas, antigos documentos administrativos, etc. Paradoxalmente, a ausência de escritos conservados testemunharia sua abundância na Idade Média. A outra causa possível é certo desinteresse pelo passado, ao menos pelos testemunhos escritos, em favor de um impulso para o futuro; a recusa de se aderir às teorias humanistas italianas do século XV e seu "retorno às fontes" greco-romanas poderiam ser uma evidência disso.

Susani S. L. França e Leandro Alves Teodoro - Acerca dos deslocamentos recentes da historiografia medievalista, é possível dizer que a história escrita em Portugal e Espanha vem deixando de lado o nacionalismo de que era acusada há pouco tempo? Se observarmos vários estudos nos dois países, notamos que são muito poucos os espanhóis ou portugueses que se dedicam a estudar a história de outros países e que ainda há um predomínio das referências locais. Pode-se afirmar que esta é uma tendência mais acentuada na Península do que em outros países?

Adeline Rucquoi - É verdade que a imensa maioria dos medievalistas da Península Ibérica a tomam como objeto de estudo, limitando-se a uma região ou mesmo a parte de uma região. Eles não são, contudo, os únicos no mundo assim, pois o interesse por espaços diferentes do seu é que é a exceção. Eu penso que tudo depende da definição que é dada de história e da função que lhe é atribuída em cada país. Não devemos esquecer que o ensino de história, sobretudo antiga e medieval, é dado em instituições públicas que não apostam em disciplinas sem utilidade. Se a 
história se tornou, no século XIX, matéria universitária, foi, sem dúvida, para fomentar um espírito cívico, uma dedicação à pátria, um melhor conhecimento dela. O conhecimento de outras histórias, de outros povos, pôde responder a motivações bélicas, ao empreendimento colonial e às políticas comerciais. Raramente, ao conhecimento por si, salvo como fator de prestígio internacional.

Se a imensa maioria dos estudantes de história escolhe estudar seu próprio país e uma região limitada ao seio dela, é em primeiro lugar porque seus estudos anteriores o levaram a isso: há uma reprodução do modelo, atitude que está ligada a certa preguiça intelectual. Isso se explica também em razão dos cargos e das possibilidades de trabalhos que estão voltados para estudos regionais, sobretudo aqueles que podem ter retorno econômico. $\mathrm{Na}$ Espanha, as regiões autônomas têm serviços de publicação de obras científicas e uma ou várias revistas regionais; eles não publicam jamais um tema que não esteja exclusivamente dedicado à região. Em Portugal, as autoridades locais publicam apenas trabalhos que lhes interessam diretamente. E, enquanto os governantes preocuparam-se "em expandir" um pouco os domínios estudados, criando meios de integração para os especialistas que trabalharam no exterior ou sobre outros países, uma oposição tácita e tenaz consegue desviar essas ajudas a favor daqueles que se limitam à Espanha, à França ou a Portugal, como seus professores antes deles.

Dito isto, mesmo em países como a França, a Inglaterra ou a Alemanha, onde existe uma tradição de estudos em diferentes áreas geográficas, a grande maioria dos alunos opta por se concentrar em sua aldeia, sua família, em documentos escritos em sua língua ... Eu omito aqui os países da América, como Argentina, Brasil, Canadá, Chile, Estados Unidos e, mais recentemente, o México, onde os interessados no período medieval não estão trabalhando com o passado de seu país e estão livres, portanto, para voltar sua atenção para os tempos, regiões e temas que mais lhes atraem.

O medievalista, como todo historiador, tem, desse modo, necessidade de dominar, além do latim, várias línguas vivas e, em certos casos, o hebreu, o grego e o árabe. Ele deve também viajar, pois como dizia Bernard de Chartres no século XII, enumerando as chaves do saber: "Mens humilis, studium quaerendi, vita quieta, / Scrutinium tacitum, paupertas, terra aliena".

Susani S. L. França e Leandro Alves Teodoro - A senhora julga que o acesso fácil e rápido ao conteúdo digital torna os novos estudos no campo da história medieval realizados em outras partes do mundo mais sólidos? Ou a falta de erudição ainda continua sendo um empecilho para que os jovens pesquisadores, a despeito do acesso facilitado às fontes, consigam avançar para além do simples balanço historiográfico, como muitas vezes se vê no Brasil? 
Adeline Rucquoi - A digitalização de muitas fontes e obras bibliográficas indiscutivelmente torna o trabalho medievalista mais ágil. E, especialmente, porque coloca de maneira mais rápida à sua disposição, em casa ou em seu escritório, textos que tínhamos anteriormente de pegar em bibliotecas. Na medida em que utilizamos tão bem as fontes quanto a bibliografia e os instrumentos de pesquisa (não lemos, geralmente, do começo ao fim como lemos um romance), o fato de poder encontrar rapidamente uma referência, uma citação, um artigo importante, um documento sem precisar se deslocar, se afastar de seus objetos pessoais para poder acessar à biblioteca, consultar os ficheiros e catálogos antigos, esperar um tempo mais ou menos longo por um livro solicitado e vêlo ser recusado em razão de seu estado, sem precisar, enfim, trabalhar com microfilmes quase ilegíveis (na seção de Manuscritos da BNF, por exemplo), é insubstituível. A digitalização permite, efetivamente, consultar a despeito do lugar onde se encontram as obras ou os documentos, eliminando os inconvenientes causados pela situação geográfica do pesquisador.

Eu não diria, contudo, que a digitalização "faz com que os novos estudos sobre a história medieval, realizados em outros lugares do mundo, sejam mais sólidos". A “solidez" da investigação depende do pesquisador, isto é, da validade de suas ideias, de sua capacidade de interpretar os textos que são disponibilizados, do conhecimento que adquiriu, da maneira pela qual "interroga" suas fontes e do espírito crítico com o qual se aproxima de seu tema e da bibliografia existente. A formação de um historiador não se limita ao conhecimento da paleografia, do latim, talvez do hebreu, do árabe ou do grego, e a ter lido algumas grandes obras gerais. Se o pesquisador não tem as qualidades e a formação de um historiador, morando na Europa ou em qualquer outro lugar, nada mudará: o acesso às fontes ou às obras digitalizadas não lhe servirá a nada, se não para acumular exemplos sem questionamento, sem plano e sem linha diretriz.

Susani S. L. França e Leandro Alves Teodoro - Quais são suas expectativas para o futuro da história medieval? Que caminhos ainda podem ser explorados?

Adeline Rucquoi - O historiador se debruça sobre o passado. Ele não é futurólogo! Mas se voltarmos para a ideia de que cada sociedade enfrenta problemas novos, significa que cada sociedade colocará ao período medieval (ao antigo ou ao moderno) novas questões.

Nos anos 1950-1960, o problema da fronteira do Far West suscitou numerosos estudos, que muitas vezes foram centrados na Espanha medieval, o que fez com que se tornassem uma espécie de Far West entre regiões cristãs e mulçumanas onde teria nascido uma Society organized for war [Sociedade organizada para a guerra] (James F. Powers, 1988). Na mesma época, os países desenvolvidos, que superaram as perdas da Segunda Guerra Mundial, fizeram da economia e de 
seus benefícios sociais o centro de seus interesses: num período de expansão que não parecia ter fim, os historiadores voltaram-se para a situação dos pobres e dos marginais, dos trabalhadores, dos escravos e da redistribuição (ou não) das riquezas.

Mais tarde, os movimentos feministas chamaram atenção para o lugar e o papel das mulheres na história medieval, enfatizando um tema que estava no silêncio. A difícil coexistência entre algumas comunidades definidas por sua religião, origem geográfica, cor de sua pele ou por sua orientação sexual é traduzida por uma proliferação de estudos sobre a homossexualidade, sobre a violência entre comunidades na Península Ibérica. A corrupção e a perda de credibilidade dos políticos nas democracias ocidentais colocam em questão os fundamentos e a legitimidade do poder, o que deu lugar a trabalhos sobre a legitimação e a sacralização do poder real na França medieval. A primazia dada aos sentimentos e sensações sobre o pensamento racional, próprio de nossas sociedades, é evidente nos estudos sobre as lágrimas, o riso e os sentidos.

Recentemente, face à globalização e às tendências contrárias ao ato de fechar-se em torno de si, o problema da identidade ocupa os historiadores. Podemos pensar, portanto, que as sociedades futuras, confrontadas com novos problemas, procurarão respostas na medida em que essas forem aparecendo. Pode-se também esperar que as letras voltem para o centro das atenções e que as sociedades do futuro tomem consciência de sua "utilidade" na formação dos indivíduos e dos coletivos, pois a ignorância permite todas as manipulações. Pode-se esperar que fontes incomuns sejam descobertas, como aquelas que estavam no Genizah do Cairo no final do século XIX, e que a arqueologia revelará elementos desconhecidos. Sejam novas ou antigas as fontes, é o olhar lançado pelo historiador sobre elas que determina, contudo, a vitalidade da disciplina e a sua atualidade. 